\title{
Veda negra y Mundo crudo (Patagonia satori): el retroceso de la descripción geográfica y la impresión crítica en la relación sujeto y espacio patagónico
}

\author{
Veda Negra and Mundo Crudo (Patagonia satori): the withdrawal of the \\ geographical description and (the) critical impression on the relationship \\ between subject and the Patagonian space \\ Gabriela S. Álvarez G." \\ "Doctora en Estudios Americanos, Universidad de Santiago de Chile \\ $\triangle$ gabriela.alvarez@usach.cl
}

\begin{abstract}
RESUMEN
Ricardo Costa es un escritor que se distingue por presentar en la práctica poética, una actitud reflexiva hacia temáticas como el sentido de habitar la Patagonia y el carácter del sujeto en los modos de relacionarse con el paisaje. Por eso, en el texto Veda negra, exploró en la amplitud del lenguaje poético, distanciándose de las definiciones comunes respecto a la Patagonia. Así, se asoma en los textos poéticos, el agotamiento de la trascendencia de la poética tradicional, junto a la posibilidad de encaminarse a pensar un punto de vista fundante, que subraye otras formas de habitabilidad en la Patagonia. En tanto, Mundo crudo (Patagonia satori), profundiza las inquietudes del texto anterior, mediante la experimentación contemplativa a través del satori (iluminación). El autor, busca detenerse en las situaciones como el dinamismo del lenguaje, el conjunto de subjetividades y los efectos de habitar la Patagonia. Durante esta experiencia, el sujeto del texto se reencuentra con una memoria que despliega más silencios que certezas, además de un lenguaje incapaz de aprehender la realidad en una zona en que la violencia, los pueblos flotantes y la adversidad climática, desborda todas aquellas categorías concertadas de las lecturas dadas sobre (habitar) la Patagonia.
\end{abstract}

Palabras clave: representación poética, Patagonia, habitabilidad, satori.

\begin{abstract}
Ricardo Costa is a writer which is set himself by a reflective poetic attitude towards topics such as the meaning of inhabiting the Patagonia and the subject's nature in the way they're


both related to the landscape. In this way, in his text Veda Negra, he explores the breadth of poetic language, moving away from the common conceptions regarding to Patagonia. Furthermore, it is possible to observe in his texts a depletion of the traditional significant poetry, along with the possibility of thinking on founding a point of view, to emphasize other forms of Patagonia's habitability. Furthermore, MundoCrudo (Patagonia Satori) goes deeper into the concerns of the previous text, using the contemplative experimentation through the satori (enlightenment). The author explores the dynamics of language, as well as the subjectivities' set and the effects of living in Patagonia. During this experience, the text's subject is reunited with a memory that deploys rather silence than answers, plus a language incapable of apprehending the reality in a zone where violence, as well as floating villages and climatic adversity; overflows all those categories given about Patagonia (inhabiting).

Key words: poetic representation, Patagonia, habitability, satori.

\section{INTRODUCCIÓN}

El problema de estudiar las particularidades de la literatura de regiones (o del interior), ha sido la constante referencia a sus características en función de temáticas y atributos más o menos prediseñado, y desde ahí, evaluar cuál es grado de acercamiento o distancia de los textos literarios con dichas pautas. En el caso de la Patagonia, la conformación geográfica ha sido central en la poesía de corte "regionalista", constituyéndose en un patrón de escritura con determinados atributos. En especial, los retratos paisajísticos así como, la construcción de caracteres típicos derivados de la vinculación del sujeto con el espacio. La función del lenguaje es apropiarse de la grandiosidad geográfica y sus manifestaciones (la nieve, el frío, el viento, etc.) y asimismo, instalar una apología de sus habitantes. En este sentido, el discurso literario patagónico fue más afín a los avatares de la naturaleza y a los estereotipos de sus pobladores. Por consiguiente, para comprender el carácter y la importancia del discurso poético en la Patagonia, es preciso visibilizar la posición de los actores culturales y escritores, respecto a la narrativa que definen temáticas y operaciones de validez en lo estrictamente literario.

Recurrir a los tópicos relacionados con la geografía (territorio extenso, distante, bello, desértico, etc.), no permite entrever los momentos de disputa, oposición y relectura que diferentes actores sostienen al interior de los espacios culturales patagónicos. Evaluaciones que abarcan no solo la labor creativa sino también, la discusión del papel del escritor, los nexos con el imaginario patagónico, la construcción de un campo literario y las estrategias representativas a nivel temático y de enunciación. Nuestro interés es advertir cómo en los últimos años, tanto los escritores como los hacedores culturales en la Patagonia toman la palabra, en el ejercicio de tensionar la lectura dominante de la geografía y la tipificación estereotipada de sus habitantes. El movimiento crítico participa de un debate interno y a la 
vez público, que visibiliza las diversas respuestas a los ejes mencionados.

En este contexto, nos interesa destacar el aporte de Ricardo Costa, quien mediante una reflexión del momento cultural patagónico como en su propuesta poética, revisa el estado de la escritura en y sobre la Patagonia, además de experimentar en el mismo trazo poético, el uso de un lenguaje interceptado por una geografía construida en base a un imaginario social preconcebido. En este sentido, Ricardo Costa instala una contra respuesta, en la cual el sujeto poético indica una señal de ruta que evidencia su posición en el espacio cultural y de cómo el escenario natural (la geografía patagónica), experimenta una traslación hacia una praxis doméstica, ya que las impresiones generadas por la convivencia con el espacio, reduce la magnificencia de la descripción paisajística hacia los cuadros de intimidad contemplativa:

No me atrevería a decir que mi trabajo conforma una poética. Tal vez responda más a la composición de un lenguaje que busca mimetizarse junto al clima que configura el imaginario patagónico y no a esa figura que puede percibirse desde un perfil turístico, paisajísticamente estético, o especulando con el romanticismo histórico del relato de viajeros. No creo reconocerme en este contexto. Me identifico más con lo que representa el silencio, la lectura diaria que arroja el tiempo, la distancia y la cotidianeidad del mundo: ese imaginario utópico que sí puede intuirse en un territorio muy particular, donde lo poético se da en el paisaje mismo de lo que puede construir la palabra. Y cuando digo paisaje hago referencia a lo papable del mundo, el impacto del tiempo en este espacio geográfico y el ser como protagonista contemplativo de este fenómeno (Costa, 2003, p. 39).

Costa rechaza dos tipos de miradas arraigadas en el modo de conocer el entorno sociohistórico de la Patagonia: la literatura de viaje y el discurso turístico.

La literatura de viaje operó entre el periodo colonial y el siglo XIX como una red discursiva en conexión con instituciones de poder -la Corona española, las sociedades científicas y el Estado- que calificaron todo lo visto y establecieron una estrategia dominante de acercamiento y relación con lo delimitado discursivamente. Entre sus retóricas comunes, se encuentran la sobre adjetivación del espacio, asumir el conocimiento local como propio o cambiar la toponimia indígena por la del viajero. Así, las descripciones de los diarios de viajes intentaron abarcar el mayor espacio posible, en el deseo de dominar a través de la escritura ${ }^{1}$. Por su parte, el fenómeno del turismo avanzó a pasos agigantados a partir de los años cincuenta con una lógica operatoria concreta: las prácticas de reconocimiento de un atractivo turístico, construir infraestructuras, habilitar accesos y las baterías de representaciones

1 Mary Louise Pratt (2010) analizó la estilística imperial de los exploradores británicos en el siglo XIX; es interesante en los subsiguientes escritos, la reiteración (las herencias poscoloniales) de algunas estructuras discursivas: las relaciones de dominio entre lo visto y la construcción del veedor "soy monarca de todo lo que veo". Los adjetivos estetizantes que amplían la significación de lo abordado por el observador y la apropiación del conocimiento local como propio. 
respecto al mismo atractivo. La Patagonia en la actualidad es un destino pensado como un valor transable, que mediante una política de apertura económica, difunde los escenarios naturales más rentables en el mercado del ocio, por lo tanto, la mirada turística selecciona los escenarios en que los habitantes y el paisaje son definidos como objeto de consumo.

La escritura poética en Costa no se identifica con los puntos señalados. Asume un ángulo diferenciado en el acercamiento descriptivo del paisaje y a los modos de percibir, habitar y representar los espacios expuestos ante el sujeto. Los atributos del lugar son insinuados en Costa en los límites cotidianos, en respuesta a la pregunta a cómo se habita el espacio. La imagen poética es sintética, evita el desborde descriptivo en el cual los elementos mínimos de una casa dicen lo suficiente respecto al sujeto y su entorno. Intenta transmitir, sin pretender establecer definiciones cerradas, un perfil descarnado del sujeto residente en la Patagonia, aquel que los movimientos inmigratorios, los proyectos económicos truncados o la climatización afectan en su forma de comportamiento. Por lo tanto, el autor esquiva en el uso del lenguaje la exaltación de la naturaleza, prefiere concretizar en los recovecos habituales, porque amar, cortar leña, comer y escribir son acciones interceptadas por el lugar y no es un cuadro externo donde dirigir la emoción contemplativa.

Ricardo Costa en el registro ensayístico, expone sus inquietudes sobre la creación literaria en la Patagonia. En el año 2007, publicó un trabajo de documentación histórica del desarrollo narrativo y poético en la ciudad de Neuquén (1981-2005). El objetivo era radiografiar el momento de efervescencia cultural a partir de los años ochenta. Inquietudes literarias que cuestionan la representación literaria "regional”, además de describir las iniciativas creativas. El crecimiento de publicaciones y los encuentros literarios potenció el área literaria y reactivó la participación cultural en la región:

Abonado en sus comienzos por un imaginario colectivo de marcada orientación utópica y fundacional pero esencialmente motivado por un espíritu de características “cimarrona”, las letras locales fueron consecuentes con una línea de conducta irreverente que le era común el entorno cultural de una época. De esta manera fue articulándose lo que hoy podemos considerar y rotular como campo literario de referencia (Costa, 2007, p. 21).

Costa objeta el modelo creativo anterior y posiciona una vanguardia literaria de orientación utópica y fundacional, un proceso cuya característica común era separarse de la tradición literaria preexistente. Proyecto que se suma al concepto de cimarrón, definido por el escritor Gerardo Burton (2007), ${ }^{2}$ para puntualizar una forma de proceder del sujeto

"Esa contemporaneidad de estéticas no implica mixtura. El único dato común es la falta de respeto por las aristocracias y por el talento adjudicado por la cultura oficial. Las élites no despiertan ni imponen unción; las academias los tienen sin cuidado; si la universidad no los cobija, no sirve. Los neuquinos se niegan a aceptar jerarquías, son cerriles y bizarros. Los organismos oficiales de cultura hacen su tarea, pero es raro que puedan imponer el quehacer cultural. Ni la cultura como espectáculo ni la cultura en la torre de marfil" (Burton, 2005, s.p.) 
patagónico que rechaza el estancamiento y las normas, dado que la heterogeneidad de la población y la biografía migratoria, difuminan lo establecido por el poder, las jerarquías o los moldes dispuestos. Por lo mismo, hay una carencia de un prerrequisito de lectura, ya que actúan en contra de cualquier diseño capaz de inmovilizar la voluntad del sujeto patagónico:

Hoy en Neuquén -y acaso en la región- una intensa producción cultural con una expresión plebeya y cimarrona que no responde a, y por el contrario, precisamente escapa de, los cánones y las ortodoxias y se precia de ser así. Esta cultura bizarra no es más que la expresión de una sociedad convertida en un caldero que de una sociedad convertida a lo oficial, construye formas alternativas que transcurren por andariveles lejanos del poder establecido (Burton, 2007, s.p).

De alguna manera, la literatura "regional" es un obstáculo en el avance hacia el desarrollo cultural en la Patagonia. Los adjetivos reiterativos y los tópicos manoseados, paralizan el crecimiento de un espacio de reflexión sobre el oficio de la escritura, y de interrogar si lo geográfico es el único criterio a tomar en cuenta para construir un campo literario. De ahí la importancia de la poeta e investigadora Irma Cuña, considerada un referente en sintonía con la inquietud de los jóvenes escritores. Interesante es la objeción de Cuña a la significación de "nacido y criado" (la posición del escritor), ya que el relato folklórico y costumbrista constituye un desafío problemático para el ejercicio creativo, por ello propone la literatura querencial. La querencia es la "tendencia o inclinación de una persona o un animal hacia un lugar conocido" (RAE, 2013); noción que expresa la opción por un lugar y evita el encasillamiento de la literatura creada en la zona conforme al origen del autor:

[...] uno de los territorios que trasciende la poesía de Irma Cuña es aquel que designarían palabra como "patagónica” o “argentina”: la poesía que logra serlo no debería tener la medida de lo geográfico, ni siquiera con el pretexto de la identidad. La arena y el viento patagónicos están, a veces, en la poesía de Irma, pero no son la poesía de Irma. La patria -la matria- de un poeta es la lengua en que escribe. También lo son, en ocasiones, ciertos derroteros existenciales que no pueden cifrarse en una región. En este caso, el ser mujer y la diáspora (Fanese, 2005, pp. 191-193).

En resumen, el texto de Ricardo Costa Un referente fundacional (2007) exploró las organizaciones y grupos en torno a la producción literaria (El Centro de Escritores Patagónicos, la revista Coirón, el grupo de Poesía en Trámite, otros), sitios fértiles en la captación del capital literario, en el camino de visibilizar los cambios representativos del imaginario en la región patagónica. A pesar de construir una fortaleza creativa capaz de integrar una "base de referencia”, según Costa, no dejan de ser iniciativas particulares porque no existe un trasvasije dentro de los programas de enseñanza en los colegios, ni tampoco se logra una 
mayor difusión en la esfera pública.

\section{VEDA NEGRA}

Las publicaciones poéticas de Ricardo Costa Veda negra(2001) y Mundo crudo(Patagonia satori) (2005), formulan de manera colateral las afirmaciones y búsquedas que lo inquieta. Veda negra enuncia un discurso perspicaz de carácter exploratorio para resolver aspectos en el terreno de la escritura y el ejercicio de la residencia. Mundo crudo en cambio, apuesta por una experiencia de elevación contemplativa sin perder de vista la posición de referencia. El sujeto individual y colectivo es testigo del proceso de comprensión y construcción de una mirada diferente. Un momento premeditado de reflexión, con el objeto de conquistar un nuevo punto del devenir socio histórico en la Patagonia.

La ruta poética en Veda negra está hambrienta de señalética, aunque la evidencia encontrada poco puede decir más que los recurrentes tópicos que, como palos ciegos, transcriben una representación continua incluida en la postal turística, la épica viajera o en la "melancolía heredada". La apelación a una mirada insinuante de otra estrategia, es un gesto resistente a la construcción repetitiva en el ámbito poético. Entonces, es necesario en la búsqueda de Costa, perder de vista el paisaje y recuperarla en el margen de acción del individuo. La idealización espacial o la exuberancia descriptiva (negativa o positiva), se interrumpe frente a lo tenue del minimalismo, que dice mucho más sobre el lenguaje en la operación de interlocución con un espacio cultural diferenciado:

\section{Velocidad crucero \\ A Cristián Aliaga}

El pensamiento se queda con esta imagen:

un pedazo de ropa clavada en el alambrado

y sacudida por el viento.

El ojo ambicioso.

Se queda con la curva que forma la ropa en el aire.

La púa del alambre tiene mucho de lenguaje.

Se aferra a cada fleco del trapo

como la palabra a la idea

que está próxima

a rasgarse.

El alambrado se continúa poste tras poste

y la distancia entre pensamiento y lenguaje

se borra en el último punto de la ruta.

Una recta en el desierto no dice nada 
porque ahora la distancia se ha convertido

en un plano donde todo es lejano,

donde todo está por suceder,

mientras el pensamiento transcurre

en la mirada del que conduce.

Este trapo fue la vestidura de alguien que

alguna vez

también condujo por esta desolación y

que también

tuvo un pensamiento alambrado por el lenguaje.

Entonces, el tiempo real del pensamiento

no es la púa que desgarra al trapo

ni el viento colgado en una curva.

Es la mirada del que conduce

buscando en el horizonte

un lenguaje a donde

llegar (Costa, 2001, p. 8).

La dedicatoria a Cristián Aliaga, señala el grado el compromiso de ambos escritores, por fomentar el crecimiento y difusión de una escritura cuestionadora del protagonismo geográfico, y más afín, con una postura de interpelación al lenguaje o de búsqueda temática, más lejana a los enfoques representativos anteriores.

La composición de frases sintéticas en "Velocidad crucero", decantan hacia el final del texto a modo de resolver la premisa entre lenguaje y pensamiento (qué es y cómo actúa), como objetivo inicial del poema. La expresión poética ocupante del sistema de signos, reincide en la referencia cultural que se traslada a una imagen concreta (la ropa colgada en el alambre). El objeto cotidiano concentra la discusión sobre la capacidad significativa de la palabra en un espacio específico, en el cual la extensión de sus señales puede entramparse en un inventario de sentido (el alambre), que cerquen la representación del imaginario en un resumen demasiado conocido. La ropa en el alambre es el detalle no visible en el desierto, de ahí que la conducción en la extensión desértica, anuncie la fracción de dos tipos de mirada: la literatura de viaje (soy dueño de lo que veo), y el enfoque derivado de la soledad y la distancia. Por lo tanto, la creación poética es un arduo trabajo con un lenguaje siempre a punto de rasgarse, que puede aprehender la ambigüedad, la tensión y el fracaso en una escritura cuya meta parece esfumarse.

Trazar una posición cultural específica, abrió el debate de cómo enraizarse con una perspectiva alternativa: "la forma más sencilla de celebrar una fundación / es marcar un punto junto al vacío. / Un punto es una partícula del todo imponiéndose sobre la nada" (Costa, 2001, p. 9). El reclamo por un punto de vista, remite a un momento fundante. 
La imagen del desierto es un concepto problemático en los círculos culturales y literarios en la región. Tal como lo indica la escritora Claudia Sastre (2008), existe una dificultad de aceptar el concepto de fundación asociado a las acepciones de vacío y nada. Básicamente, porque son categorías usadas en diversos discursos que edificaron determinados valores y características en la constitución del imaginario patagónico:

La idea de fundación implica per se una idea de vaciamiento, no se funda sobre algo: se funda sobre la nada. Esa idea de la "nada" arrastra su carga semántica en toda la literatura patagónica, y la única manera de desarticular los presupuestos es a través del reconocimiento de que existía algo antes, y eso ya lo sabemos: toda la literatura oral aborigen -llamada oralitura- $y$, como es debido la escritura de viajeros y cronistas (Sastre, 2008, s.p.).

El sentido de la nada en el trabajo de Costa, es una acción consciente por encontrar un enfoque en una instancia crítica de cómo escribir desligado de las temáticas comunes en el área patagónica. Costa lo entiende como un pilar donde los planes individuales y colectivos ubican sus cuerpos en un espacio de reflexión: "sobre uno de estos puntos estamos nosotros. / Abrazándonos y girando en un vacío que nos mantiene / flotando sobre el silencio absoluto" (Costa, 2001, p. 9). Flotar alrededor de una marca es similar al movimiento de la ropa colgada resistente al viento, una colectividad compenetrada en una ruta común, dichosa del carácter inmaterial de sus figuras, como si la invisibilidad tallara una oscura fuerza: "nadie sabe que flotamos/ (...) flotar abrazados a la idea de la nada/ mientras los cuerpos se mueven y la fundación se convierte /en un acto de amor junto al vacío (Costa, 2001, p. 9).

Recordemos la conclusión del autor, que gran parte de las iniciativas literarias son productos de la conjunción de voluntades, pero están desvinculadas de los planes educativos en los colegios, además de lo público. Tanto el acto de escribir poesía como habitar los pueblos patagónicos, son prácticas sociales que comparten una tozudez carente de explicación lógica. Parámetro que presiona a nivel de sentido, los estereotipos más comunes que definen la geografía (personas y lugares). En su reemplazo, la poesía de Costa prefiere la insinuación o una definición que inmediatamente rechaza. Por ejemplo, en la representación de los amantes, el espacio externo es algo aparentemente ajeno a los movimientos dentro de la habitación, sin embargo la relación entre los sujetos transmite las consecuencias del fenómeno de la distancia ${ }^{3}$. El encuentro amoroso enuncia esta potencia invisible retratada a modo de un bosquejo, en que los cuerpos solidarizan por un instante con el peso de vacío que cargan cada uno. En otras palabras, el acto de amor marcado por la distancia, reitera una energía invisible, pero terca que reclama un

La longitud espacial entre un punto y otro no define la distancia geográfica en el texto de Costa, sino cómo se vive la sensación de distancia. Los sujetos proyectan esta desvinculación con las otras personas, a pesar del contacto ceñido de los cuerpos. 
punto de enunciación dentro de la nada tan categórica:

\section{Lectura}

[...]Aquí, tu silencio y la noche apenas se sostienen.

Dos almas separadas en el mundo y recorridas

por una escritura que obliga a la lectura

de un resumen inconcluso (...)

Ahora, en algún lugar de este mundo, una mujer

que te conoció y que también mastica ese viento,

se ha quedado cociendo legumbres en la casa.

Ella sabe que el secreto de su arte está en el paisaje

de tu boca y eso te preocupa.

Aunque el resumen de lo vivido sea ese viento que separa

almas durante la noche, el paisaje siempre será el mismo (...)

(Costa, 2001, p. 12).

Veda negra es una aproximación poética a una subjetividad impresa en una realidad patagónica en ocasiones muy difícil. Pese a esto, el paisaje no deja de ser un cuadro externo en la escritura de Costa, porque le llama más la atención las posibilidades del verbo habitar: la inquietud que le despierta el excesivo realismo en las historias mínimas, cruzadas por la violencia, la matanza, el abandono o la climatización. Por ende, contestar con la construcción de figuras persistentes es parte de la búsqueda del autor, por un lenguaje coincidente con esta manera de ver la realidad, que está más allá de las atribuciones del signo y que no puede negarse, ni afirmarse, no obstante es: "lo cierto que la poesía adhiere a este tipo de celebraciones./ Salvo que uno cree comer lo que no le sirven, /bailan una música que nadie toca / y disfruta una compañía / que aún no se pronuncia” (Costa, 2001, p. 33).

\section{MUNDO CRUDO (PATAGONIA SATORI)}

El preludio del libro, es la cita del Lama Dhangarhi Pampa, de escoger el término satori para indicar el ascenso de la mente fuera del cuerpo: "ese estado de pureza espiritual por el cual el mundo deja de existir y el tiempo se desvanece junto al sentido material del ser" (Costa, 2007). La derivación de esta experiencia es una contemplación que no apela a la trascendencia del objeto ni del sujeto, ya que ambos son considerados pensamientos.

Son tres conceptos que alude al despegue contemplativo señalado por el maestro: nirvana, samadhi y satori. El nirvana es la imagen más extrema que define la liberación absoluta: "la felicidad plena obtenida por la pérdida de la individualidad y la incorporación en la esencia divina” (RAE, 2003). El simadhi y el satori son rupturas, pero con diferentes grado. El primero, impide retornar a un punto de origen una vez que el sujeto experimenta grados 
el quiebre, en cambio el satori, manifiesta un comienzo y un final, sin perder la capacidad de recordar el motivo de la apertura comprensiva, es decir expresa una instancia de iluminación tras la adquisición de un nuevo conocimiento, debido a la claridad perceptiva del sujeto:

El conocedor puede guardar como un recuerdo este vislumbre. Puede respirar por él, puede desearlo, puede acariciarlo, puede esforzarse de nuevo por experimentarlo, pero él está todavía ahí. Aquel que ha tenido una vislumbre, aquél que lo ha visto está ahí [...]. En el instante en que el samadhi sucede, tú no está allí para recordarlo. El samadhi nunca se convierte en parte de la memoria porque el que estaba allí ya no está. Como dice en Zen: "El hombre viejo ha desaparecido y el nuevo ha llegado y esos dos nunca se encuentran"(Osho, 1998, s.p.).

En este sentido, la internación poética en Mundo crudo, proyecta entre los suburbios de lo real y la creación poética, los nexos que promueven el carácter representativo del imaginario en un contexto específico. A través del satori, el sujeto obtiene un nuevo punto de vista en la contemplación del mundo, capaz de trascender los márgenes individuales, en pos de una conciencia colectiva, opuesta al simple entendimiento lógico e intelectual.

Mundo crudo asume las particularidades del satori, para reflexionar el vínculo espaciosujeto y la forma de mirar dicho espacio. A partir de la localización de la mirada, el texto pone el acento en la problemática de la habitabilidad y de la capacidad de aprehensión del lenguaje poético, en el cual los emplazamientos patagónicos o los efectos del clima, por nombrar algunos, aclaran en parte los modos de vida y de actuar de sus habitantes, que el texto poético desea comprender, aun cuando en este proceso decaiga.

Inmediatamente de la cita en "Satori I", el autor agrega como epígrafe un fragmento del poema "En el camino" de Jorge Spíndola: "todo es pasado, todo está por suceder" (2002). La oposición paradójica de la frase, delata una actitud de sentencia dentro del texto, en cuanto a la limitación de delinear por algún medio, aquello que se ubica en un horizonte móvil y esquivo. Las sensaciones de recorrer la pampa desértica en el texto, se inserta en un itinerario tedioso y agotador, de una perspectiva fuera de su alcance, un viaje interrumpido por las grietas de un animal, ubicado en el margen de los sitios maravillosos celebrados por el ojo extranjero. La frase destacada por Costa, construye una imagen descarnada de un pasado remoto que se confunde con la cronología futura. La circularidad evidente del tiempo, sin embargo, sugiere una salida en el código poético, a la vinculación entre sujeto y espacio, cercado por representaciones reiterativas que, alimentan las lecturas comunes en la zona patagónica.

La senda es destituir en el texto poético los honores de antaño, lo épico y lo maravilloso descritos en los distintos registros que encasillan en estereotipos cerrados y fijos a los pobladores y el paisaje. La reflexión de estas materias, apunta hacia un conjunto de problemas a nivel de representación que obliga en primera instancia, a exponer el punto 
donde la aprehensión poética retorna a la cuestión espacial, y desde ahí, replicar si el entorno constituye un núcleo básico en la construcción poética:

\section{Patagonia satori}

Abandonado junto a un viejo Renault gris en el kilómetro mil quinientos setenta y ocho, él teme que su reflexión no incluya al mundo ni a ninguna discusión que afecte la problemática del ser y del no ser.

Duda y su reflexión se pliega a la deriva del jote que sobrevuela la sequedad de este páramo.

Tanto desde arriba como desde abajo, hombre y pájaro se demoran contemplando una extensión infinita. Para el jote, el ritual culmina cuando descubre el objeto deseado. y su vuelo se inclina para precipitarse sobre la víctima.

En cambio para él todo comienza cuando entiende que no existe otro objeto deseado. más que los motivos de su propia existencia.

Entonces reconoce que una filosofía inquietante no debería cargar con el cuerpo de alguien que propone una conjetura débil entre tanto abandono.

Así regresa al punto del cual nunca debió partir, el cual acepta como destino del único mundo que le toca vivir; el que escucha masticar el tiempo se eterniza en una poética del silencio y la espera vuelve a oscurecerse porque el pensamiento no progresa y aquí no ha pasado nada (Costa, 2005, p. 4).

En la pampa, la atención se centra en las decisiones del ave y del sujeto por elegir una alternativa para conocer una materialidad escurridiza. El ave despeja el enigma con el sobrevuelo directo hacia el objeto deseado, desde el cual surge la polémica, puesto que el sujeto le resta a la movilidad la capacidad resolutiva de reflejar la apertura contemplativa (satori). Entonces, el texto anuncia otra fórmula donde la geografía retroceda: expandirse por los terrenos conocidos y desde ahí, avistar las realidades que el sujeto del texto le inquieta. La dimensión cotidiana será el eje donde testificar esta actitud iluminadora del sujeto, en una inmovilidad del que no puede adelantar ningún suceso o pensamiento.

Mundo crudo, coincide con el concepto de literatura querencial propuesto por Irma Cuña -la tendencia del sujeto o animal por un espacio conocido-, es decir optar por una posición desde el cual ejercer el acto discursivo (la emisión y sus efectos), y apelar a un 
cambio en el modo de mirar un espacio cultural altamente descrito. No obstante, abandonar los pasos anteriores y fundar otro punto de vista, implica un borrador radical no exento de dificultades.

Por eso, indagar en las posibilidades del lenguaje, manifiesta un paso importante en la generación de formas expresivas desterradas de los mecanismos representativos tradicionales. Por ejemplo, en "Antiguo alfabeto", el sujeto del texto no logra recordar su vida en el desierto, pese a que otra persona lo testifica. El estado inicial es el olvido, pero inmediatamente, el sujeto manifiesta la convicción de mantenerse donde está, porque tanto los hábitos diarios como la escritura son sitios para desmontar los dispositivos de la memoria:

ese lugar en el que nunca estuve, en el que te escucho decir lo feliz que fuimos.

se lo ha llevado todo sin que nunca supiese que el mundo me había elegido para estar allí.

Aquí, sobre esta mesa, hago el trabajo de todos los días: caliento el agua, trozo el pan, comparto el almuerzo, pero aún no he estado en ese lugar que puedo reconocer mientras escribo" (Costa, 2005, p. 7).

En general, el lenguaje constituye un instrumento de articulación de los pensamientos y los sentimientos. La forma de comunicación en una comunidad social participante de los mismos códigos. También es la ruta de interacción entre el sujeto y el mundo (nombrar), como la capacidad de construir otras significaciones de la realidad. La segunda opción nos habla del carácter performativo del lenguaje.

Lo performativo se puede entender como "la capacidad del lenguaje en funcionamiento para instaurar realidades en el mundo" (Aguilar, 2007, p. 2). Dicha competencia sería un punto de inflexión en la articulación mecánica de ésta (la construcción de sentidos); sin embargo, el atributo performativo del lenguaje no escapa totalmente de los mecanismos de instrumentalización del signo, observable en la inserción del poder:

En la semiosis social los textos son instrumentos del sentido que generan y sostienen, pero ese sentido es dramáticamente elusivo, como lo son las condiciones pragmáticas que la sustentan. Entre esas condiciones se encuentran también condiciones de textualidad que remiten a un determinado grupo humano, a cierto momento histórico, a un pacto de lectura, a una competencia textual social y sobre todo a la distancia que media entre el texto y la intención pragmática del enunciador. Esa intención pragmática es el origen de la segunda instrumentalidad del lenguaje. Precisamente en esta segunda instrumentalidad es donde reside el carácter performativo del discurso, que está íntimamente unido a la posibilidad de configurar un sentido posible (Aguilar, 2007, p. 3). 
Entonces, la interacción comunicativa es un espacio de acuerdo y disputa que traspasa la esfera lingüística, e ingresa en la problemática social y en el uso práctico e intencionado del lenguaje. Justamente, el libro de Costa, analiza el hecho escriturario con el propósito de generar una referencia deshabitada del imaginario representativo establecido: "lo hago para fundar cierta memoria en el exilio de una escritura que comienza a pronunciarse. / Aquí, donde las palabras desbordan el ritmo que las ordenan/ se esmera por dejarme afuera" (Costa, 2005, p. 7). La peculiaridad performativa se relaciona con el sentido fundacional del lenguaje. El texto poético reúne los fragmentos discursivos más comunes y los representa en una imagen poética mediante un movimiento circular insistente. El círculo sería capaz de detenerse en el límite de los rastros dejados por otros, aquí, el sujeto del texto encuentra una senda y así, alcanzar la mudez testimonial de la palabra:

sin embargo, en este vagar junto a tu lado, continúo escuchándote hablar de ese desierto en el que estuve y del que solo conozco las pocas letras de un alfabeto antiguo Creo que siempre será así: uno que apura la memoria del otro,

que lo atropella para que ocupe un mismo lugar sin saber que el mundo nos ha elegido aunque las palabras no digan nada (Costa, 2005, p. 7).

Aceptar de antemano, sin cuestionamiento las herencias textuales, limita la generación de nuevos sentidos. La fuerza reproductiva del desierto, frustra la apertura perceptiva. Para zanjar este dilema, "Novela histórica" propone que se excluya el relato de la memoria y la verosimilitud de la palabra, y así, concentrarse en la potencia de la apreciación. Mirar desde una marca previamente seleccionada:

existe una forma de narrar el pasado

sin recurrir al texto de la memoria

o a la fe de las palabras, como es

contemplar en silencio, aunque todo insista en repetirse sobre los despojos de lo que vamos abandonando(Costa, 2005, p. 2).

De acuerdo al texto, instalarse en un lugar desde el cual contemplar el fenómeno de la habitabilidad, descoloca la situación curva del sujeto del desierto. La cotidianidad difumina el peso repetitivo del tiempo, además de la descripción espacial. Así, lo inabarcable en el texto poético no sería el paisaje patagónico, sino la subjetividad franqueada por las categorías del vacío, la distancia, la soledad y los efectos del clima. Visible en la coexistencia de los sujetos, en el cual se insinúa un perfil y al mismo tiempo se busca superarlo: 
los hechos hace que ahora nos miremos

como un suceso sin tiempo, como dos eternos

conocidos que vuelven a extraviarse

en el comienzo de la noche

con las mismas cosas por decir

pero sin abandonar la posibilidad

de dejar de ser, más allá

de su propia existencia (Costa, 2005, p. 12).

Ricardo Costa en Veda negra, concretiza en imágenes poéticas la cuestión de la residencia en la Patagonia, como la incapacidad de los amantes de unirse producto de la misma soledad que ambos comparten. Lo anterior, lleva a Costa a indicar el carácter animal, por la resistencia a la domesticación, elementos que desarrolla en Mundo crudo: "como si estuviera paseándose por una flaca pastura / con hambre de fiera. / Así de animal revolcándose dolido entre la sequedad de las palabras(Costa, 2005, p. 33).

Aspecto que replica en el texto "Cave canem" -cuidado con el perro- ${ }^{4}$. Una sentencia para quienes disputan las partes de un cuerpo textual imposible de atrapar, debido a la movilidad del objeto deseado. La jauría de perros grafica la contemplación crítica del libro por los desafortunados del desierto, la marginalidad existencial y la invisibilidad suscitada por la adversidad de una historia socio-cultural, en que los sujetos que la habitan se defienden como animales:

\section{Cave canem}

Parecíamos una jauría: todos detrás de la misma presa, aunque a ninguno le preocupaba el hambre del otro.

Tampoco escuchábamos los gritos de la multitud ni respondíamos a los accidentes del terreno.

Sólo corríamos.

Siempre corríamos.

Corríamos procurando no perder de vista lo que nunca dejaba de fugarse (...).

Desafortunadamente, nada quedó escrito sobre esta bestialidad;

la que pretendía conocer la naturaleza del instinto que nos arrastraba tras lo deseado.

Nunca llegábamos pero siempre corríamos (...).

4 Se cree que la ciudad de Pompeya fue destruida por la erupción del Vesubio en el año 79 D.C., entre sus ruinas, se encuentra la Casa del Poeta Trágico. En el umbral todavía es visible un mosaico con la inscripción de "cave canem" que significa cuidado con el perro. 
no existe sabiduría que pueda anticipar el destino

de lo que debemos buscar.

Sin embargo, después de tantos años, uno continúa la persecución

y no se explica por qué no se detiene ante el cuerpo desgarrado

de aquel que no puede más y que agoniza

junto al camino (Costa, 2005, p. 37).

La imagen cruda del sujeto agónico, comparte cierto sentido con la propuesta de Cristián Aliaga en "La oveja"5: visibilizar seres no domesticados en los márgenes de la geografía, de la mirada descriptiva y turística. La oveja y el perro en el imaginario de estos textos, presentan el carácter de enfrentamiento de un modo de habitar Patagonia (porque siguen ahí), ya que la agonía es un estado ambiguo que demuestra una actitud terca, a modo de una quietud aparente que se percibe como testimonio de una forma de convivir con el espacio patagónico:

el que agoniza ya no vive pero tampoco termina de morir.

La única certeza es que este moribundo no correrá más

porque el motivo de la persecución ahora se posa

en los ojos del que lo está mirando y ambos se reconoce

irremediablemente condenados

por la misma naturaleza.

[...] Otro perro grotesco que pone la pata en la llaga (Costa, 2005, p. 34).

\section{CONCLUSIONES}

Observamos que en el acto de creación poética de Ricardo Costa, se pregunta desde las mismas bases de sentido (el lenguaje), si actualiza los moldes representativos en torno a la Patagonia. En otras palabras, la apuesta del autor es buscar los atributos de una mirada reveladora de un mundo excluido de las categorías canonizadas por la descripción geográfica y sus habitantes. Entre las inquietudes que derivan del análisis de los libros de Ricardo Costa están: ¿de qué manera representan los textos poéticos la habitabilidad en Patagonia? ¿La distancia contemplativa testifica respecto a las fronteras cotidianas del sujeto inserto en un determinado contexto?

\footnotetext{
“Atrapada por el cuello al alambre de púas, un mal movimiento la degollaría. La oveja desliza milímetros su cabeza hasta quedar inmóvil a la espera de una solución que escapa a sus propios movimientos. Su cabeza no piensa, ni esboza cursos de acción, apenas percibe el suave ardor de los alambres puntiagudos, mientras a unos metros del alambrado los vehículos atraviesan la soledad. Pasan sin verla, o ven apenas la imagen fugaz de una oveja que permanece muy cerca de la ruta, en una inmovilidad sólo rota por gestos imperceptibles. Empieza a dolerle cuando se adormece, y así se despierta, y vuelven a nublarse sus ojos azules hasta que regresa el dolor que para ella no tiene nombre. No puede estimar la duración de la noche ni aspira al azar de alguien que atine a separar su cabeza del alambre" (Aliaga, 2009, p. 90).
} 
En primer lugar, analizamos Veda negra, texto que explora la amplitud del lenguaje poético, lejos de los tópicos comunes. La fatiga de la tradición discursiva es una oposición invisible que recorre todo el texto poético, con el objetivo de fundar un nuevo punto de vista, generador de nuevos sentidos sobre el espacio patagónico. Para ello, primero se necesitó la pérdida de protagonismo de la geografía (solo insinuado), y desde ahí, codificar cómo el lugar se difumina hacia una traslación cruzada por el testimonio práctico de la habitabilidad.

En cambio Mundo Crudo, profundiza estas inquietudes mediante la contemplación (satori). El texto poético se detiene en las condiciones de una mirada centrada en los problemas del dinamismo del lenguaje, la conjugación de subjetividades en la región y los efectos de cohabitar el espacio patagónico. Durante la inmovilidad crítica, el sujeto del texto se reencuentra con los trazos de una memoria que habla más de silencio que de certezas, y que el lenguaje a su vez, no puede cabalmente aprehender la variabilidad de las realidades en una zona, en que la violencia, los pueblos flotantes y la adversidad climática, desbordan las categorías concertadas. El lenguaje es una frontera tragada por el silencio agónico de seres cuyo comportamiento animal, resisten a cualquier categoría que puedan reducirlos a simples maquetas. Por eso, en el último texto, no necesita de la percepción panorámica para encontrar las respuestas a la problemática de la escritura y los efectos de habitar la región. El juicio crítico solo indica su posición y resistir como la ropa colgada en el alambre, para fundar otra mirada sorda de sus anteriores lecciones.

\section{REFERENCIAS}

Aliaga, C. (2009). Música desconocida para viajes. Buenos Aires: Desde la gente.

Aguilar, H. (2007). La performatividad o la técnica de la construcción de la subjetividad. Borradores. 7/ 2da. Época, 1-8.

Burton, G. (2005) Neuquén, una cultura cimarrona [en línea]. Escritores patagónicos. Disponible en: http://www.escritorespatagonicos.8m.com [Consulta: 13 de marzo 2013].

Costa, R. (2007). Un referente fundacional: las letras neuquinas (periodo 1985-2005) y su (in) transferencia en el campo educativo. Buenos Aires: Suri Porfiado.

Costa, R. (2003). El paisaje de la palabra. La Pecera, 5, III, 37-43.

Costa, R. (2005). Mundo crudo (Patagonia satori). Neuquén: Limón.

Costa, R. (2001). Veda Negra. Buenos Aires: Pez Náufrago. Ediciones Del Dock.

Diccionario de la Real Academia Española (Vigésima edición). Disponible en: htpp://www.rae. es [Consulta: 14 de marzo 2013].

Fanese, G. (2005). Irma Cuña, poeta [en línea) La aljaba, 9. Disponible en: http://www.scielo. org.ar/scielo.php?script=sci_arttext\&pid=S1669-57042005000100011\&lng=es\&tlng= es.

Pratt, M. (2010). Ojos imperiales. Literatura de viajes y transculturación. México: Fondo de Cultura Económica. 
Sastre, C. (2008). El lugar del escritor como actor social e intelectual. $3^{\text {a }}$ parte, Ricardo Costa "Mundo Crudo (Patagonia satori) [en línea]. Verbo Copihue. Ensayo, literatura y crítica desde la Patagonia. Disponible en: http://verbocopihue.blogspot.cl/search/label/El\%20 lugar\%20del\%20Escritor\%3A\%20sobre\%20Ricardo\%20Costa [Consulta: 03 de marzo 2011].

Spíndola, J. (2002). Calles laterales. Trelew: Sur del mundo.

Osho (1998). Meditación: el arte del éxtasis [en línea]. Disponible en: http://www.oshogulaab. com 